\title{
Effect of chronic diseases of lifestyle knowledge on readiness for change among long-distance microbus drivers in Giza, Egypt
}

F.A.A. Ibrahim

$$
\begin{aligned}
& \text { أثر المعارف عن الأمر اض المزمنة التي تنجم عن أنهاط الحياة حول تقبّل التغير بين سائقي الحافلات الصغيرة لمسافات طويلة في } \\
& \text { الجيزة، مصر أئر المعارف عند } \\
& \text { فاطمة عبد العليم عبد الغني إبراهيم }
\end{aligned}
$$

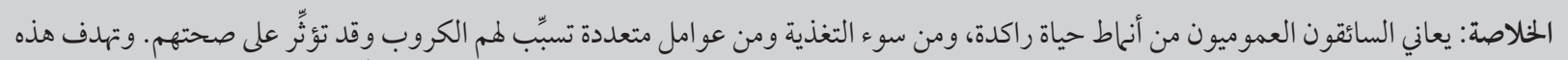

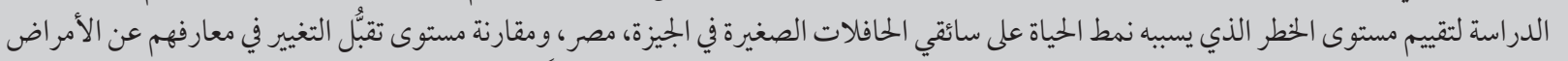

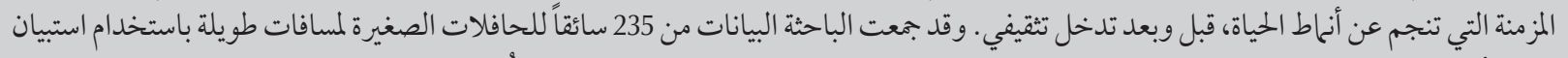

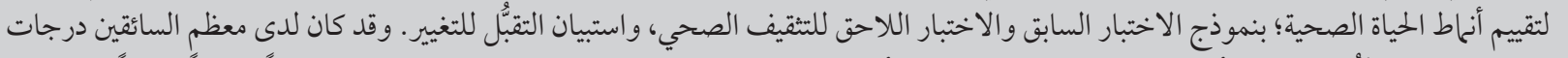

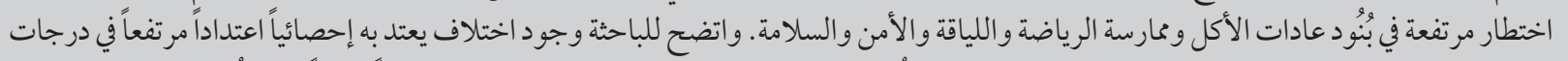

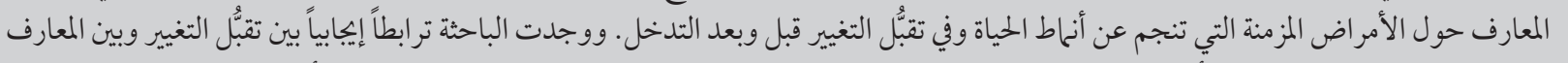

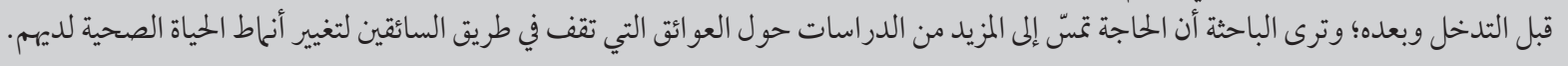

ABSTRACT Commercial drivers suffer from sedentary lifestyles, poor nutrition and numerous stressors that can impact their health. This study aimed to assess the health lifestyle risk level of microbus drivers in Giza, Egypt, and to compare their level of readiness for change with their knowledge about chronic diseases of lifestyle, before and after an educational intervention. Data were collected from 235 long-distance microbus drivers via a health lifestyle assessment questionnaire, pre-post-tests of a health education module, and the readiness for change questionnaire. The majority of drivers had high risk scores in the eating habits, exercises/fitness and safety sections. A highly significant difference was found in chronic diseases of lifestyle knowledge scores and in readiness for change scores before and after the intervention. A positive correlation was found between readiness for change and knowledge pre- and post-intervention. Further studies are needed of barriers for drivers to change their health lifestyles.

Effet de la connaissance des maladies chroniques liées au mode de vie sur la disposition au changement chez des conducteurs de minibus longue distance à Giza (Égypte)

RÉSUMÉ Les conducteurs de véhicules utilitaires souffrent de sédentarité, d'une mauvaise alimentation et de nombreux facteurs de stress qui peuvent avoir des répercussions sur leur santé. La présente étude visait à évaluer le niveau de risque sanitaire associé au mode de vie encouru par les conducteurs de minibus à Giza (Égypte), et à comparer leur degré de disposition au changement en fonction de leurs connaissances sur les maladies chroniques liées au mode de vie, avant puis après une intervention éducative. Les données ont été recueillies auprès de 235 conducteurs de minibus longue distance à l'aide d'un questionnaire de santé évaluant le mode de vie, de tests réalisés avant et après le module d'éducation sanitaire, et d'un questionnaire évaluant la disposition au changement. La majorité des conducteurs ont obtenu des scores de risque élevés pour les sections correspondant aux habitudes alimentaires, à l'exercice/la forme physique et à la sécurité. La différence était très marquée entre les scores obtenus avant et après l'intervention pour les maladies chroniques liées au mode de vie et pour la disposition au changement. Une corrélation positive a été trouvée entre la disposition au changement et les connaissances avant et après l'intervention. Des études supplémentaires sont requises pour identifier les obstacles qui empêchent les conducteurs de modifier leur mode de vie. 


\section{Introduction}

Chronic diseases of lifestyle (CDL), also called noncommunicable diseases, are a group of diseases that share risk factors such as unhealthy dietary choices, smoking, lack of physical exercise, sedentary behaviour and life stresses $[1,2]$. Poor lifestyle choices are strongly associated with a higher risk of heart disease, diabetes, respiratory disease and cancer; these 4 diseases are responsible for over $50 \%$ of mortality worldwide [3]. By 2030, the proportion of total global deaths due to chronic diseases is expected to increase to $70 \%$ and the global burden of disease to $56 \%$. The greatest increase is anticipated in the African and Eastern Mediterranean Regions $[4,5]$. In Egypt, chronic diseases accounted for $78 \%$ of all deaths in 2002 , well above those from communicable diseases (18\%) and injuries (4\%) [4].

Certain occupations predispose workers to many of these health issues. Commercial drivers suffer from sedentary lifestyles that affect their state of physical fitness, a lack of healthy food choices at truck stops leads to poor nutrition, while numerous occupational stressors can impact their health, lead to use and abuse of alcohol and other chemical substances or cause fatigue, sleep disorders and other conditions that have driving safety implications [6-10]. Health intervention programmes have been recommended to promote regular exercise, healthy eating, no smoking and weight control in professional drivers $[7,11]$. Education interventions, however, work best if they match a person's state of readiness to change. Interventions that are not staged to the readiness of the individual will be less likely to succeed, while interventions that try to move a person too quickly through the stages of change are more likely to create resistance that will impede behaviour change $[12,13]$.

The aims of the present study were to assess the health lifestyle risk level of long-distance microbus drivers in Giza,
Egypt and to compare their level of readiness for change with their knowledge about CDL, before and after an educational intervention.

\section{Method}

\section{Study design}

Using a quasi-experimental study design the long-distance microbus drivers were assessed initially for health lifestyle risk level and then their knowledge about CDL and readiness for change were measured and compared before and after receiving an intervention in the form of a health education module.

\section{Setting}

The study was carried out from June 2010 to September 2011 at Al Monib bus station in Giza governorate, Egypt. Giza is the third largest city in Egypt and is located on the west bank of the River Nile, some $20 \mathrm{~km}$ south-west of central Cairo. The city's population was 2681863 in the 2006 national census, while Giza governorate had 6272571 at the same census.

\section{Sampling}

Permission was sought and received from the authority in charge of the bus station. A total of 235 long-distance microbus drivers out of 600 participated were recruited to the study by convenience sampling. Selection of the study participants was done during their breaks at the bus station and while waiting for passengers. The researcher approached drivers, introduced her professional affiliation, explained the purpose and nature of the present study and invited them to participate. The criteria for inclusion were drivers who had no history of CDL included in the intervention of the present study (stroke, diabetes, cancer, heart diseases or bronchial asthma), as verbally reported by the study participants.

\section{Tools for data collection}

Three tools were used to collect the data. In addition, a data sheet was used to record the study participants' sociodemographic data: age, marital status, level of education, monthly income and family size responsible for.

\section{Health lifestyle assessment question- naire}

The health lifestyle assessment questionnaire-self-test was a modified version of one developed by the public health services in the United States of America [14]. It assessed health-related behaviours in 5 sections with 25 items: tobacco, alcohol and other drugs (7 items); eating habits (4 items); exercises/fitness (4 items); stress management (5 items); and safety (5 items). Each item is scored as: almost always, sometimes and almost never. In view of the presence of the almost never option, it was not felt necessary to make any modifications to the tool, even for sections concerned with alcohol consumption, drug use and exercise that may not be applicable or culturally unacceptable in this context. The scoring system was as follows for each section: scores $9-10$ $=$ excellent, scores $6-8=$ good but room for improvement, scores 3-5 = healthrelated behaviour risky, and scores $0-2$ = may be taking serious and unnecessary risks with health and possibly the health of others.

\section{Pre-and post-intervention test}

The pre- and post-intervention knowledge test was developed by the researcher based on a comprehensive literature review to test knowledge about the topics included in the health education module [15-20]. The preand post-test had 2 parts. Part 1 had 209 questions that covered 10 basic topics of healthy lifestyle aspects: nutrition (51 questions); physical exercises/ fitness (27 questions); smoking (33 questions); alcohol ( 4 questions); sexually transmitted diseases (32 questions); sleep (7 questions); accident and injury prevention (41 questions); 
hygiene (4 questions); stress management (5 questions); and periodical self-examination (5 questions). Part 2 had 66 questions that covered basic knowledge and prevention of 5 chronic diseases: stroke (4 questions); diabetes mellitus (11 questions); cancer (26 questions); heart diseases (16 questions); and bronchial asthma (9 questions). All questions were scored as correct $=1$ and incorrect $=0$. The maximum pre-post-test score was 275 and the cut-off score for an acceptable level of knowledge was 138.

\section{Readiness for change questionnaire}

The third tool was the readiness for change questionnaire which was developed by the Lifestyle Management and Nutrition company [19]. It includes 15 items, with scores interpreted as follows: score 21 to $63=$ "It's clear that changing the way the person looks, feels, and performs has become very important to him/her and he/she realizes that the way he/she is doing things right now simply isn't cutting it"; score -20 to $+20=$ "It's important for the person to stop thinking and start doing. He/she is probably frustrated with the way things are, but is afraid that changing the way he/she does things will cause more hassle and difficulty than just sitting back, doing nothing, and continuing to look and feel the way he/she does today."; score -61 to $-21=$ "It doesn't look like the person really wants to change. Is this true? Is he/she simply toying with the idea of improving his/her physical activity habits and eating habits? If so, he/she is not really ready to make a change." Item number 3 (about medications for heart disease, high blood pressure or diabetes) was modified within the same meaning to suit the study participants' criteria.

\section{Pilot study}

A pilot study was done on $10 \%$ of the study participants to assure clarity and understanding of the tools. It also helped in the estimation of the time needed to fill the data collection tools.
Accordingly, some minor modifications were made to the tools.

\section{Fieldwork}

Three structured interviews were conducted at the bus station after making appointments by phone call to select the most suitable time for drivers and to ensure their readiness, concentration and feeling at ease. These interviews were approached and handled in groups or individuals, depending on the work circumstances at the time of interview

The first interview was the orientation by the researcher for the study participants. For ethical considerations; during this orientation session a clear explanation of the nature and the aims of the study were given to the drivers to obtain their informed verbal consent which included their rights for privacy and confidentiality. Questionnaires were completed anonymously for confidentiality. At this interview the individual and sociodemographic questionnaires were completed by participants and the health lifestyle assessment and the readiness for change questionnaires were applied by the researcher. The pre-test of CDL knowledge was given to the drivers to complete at home and they were asked to return it to the researcher at the second interview which was 1 week after the first interview.

During the second interview, the pre-test questionnaire was taken from the driver, and then the study participants received the Arabic language materials of the health education module (intervention) in the form of booklet illustrated with pictures. Participants also received CD containing video films if they confirmed the availability of a computer at home or another setting to watch it. The module was demonstrated to participants and conducted through self-learning, with continuous guidance and follow-up of the researcher by phone or during fieldwork at the study setting.

At the third interview, which was conducted on average 4 weeks after the second interview depending on the drivers' pace of self-learning, the postintervention knowledge and readiness for change questionnaires were completed again by participants.

The health lifestyle assessment and readiness for change questionnaires were delivered by the researcher using the English version while the pre-posttests and the health education module (intervention) were available in simple, understandable and common Arabic language for personal use by the study participants. Each interview took an average 45 to 75 minutes to complete the data collection tools.

\section{Statistical design}

The data collected were tabulated and analysed using SPSS, version 16. Descriptive and inferential statistics were carried out including frequencies, percentages, chi-squared test, paired $t$-test and correlations. The level of significance was set at $5 \%$.

\section{Results}

\section{Background characteristics}

The ages of the study sample were grouped as $20-<40$ years (55.3\%) and $40-60$ years (44.7\%). As regards level of education, more than half of the sample had basic education (55.7\%), while others had achieved diploma or university level. Their mean monthly income was Egyptian pounds (LE) 1555. Nearly three-quarters of the study participants (72.8\%) were responsible for 6-8 family members, while the remainder were responsible for 3-5 and $\geq 9$ members. The majority of them were married (75.7\%), while only a few were divorced or widowed (Table 1).

\section{Healthy lifestyle assessment}

Table 2 shows the results in the 5 sections of the health lifestyles questionnaire according to age group. For tobacco, alcohol and other drugs the lifestyles of the great majority of 


\begin{tabular}{|c|c|c|}
\hline Variable & No. & $\%$ \\
\hline \multicolumn{3}{|l|}{ Age (years) } \\
\hline $20-<40$ & 130 & 55.3 \\
\hline $40-60$ & 105 & 44.7 \\
\hline \multicolumn{3}{|l|}{ Level of education } \\
\hline Basic education (completed 9th grade school) & 131 & 55.7 \\
\hline Diploma & 74 & 31.5 \\
\hline University & 30 & 12.8 \\
\hline \multicolumn{3}{|l|}{ Monthly income (LE) } \\
\hline $1000-<1500$ & 150 & 63.8 \\
\hline $1500-<2000$ & 83 & 35.3 \\
\hline$\geq 2000$ & 2 & 0.9 \\
\hline \multicolumn{3}{|l|}{ Family size responsible for } \\
\hline $3-5$ & 55 & 23.4 \\
\hline $6-8$ & 171 & 72.8 \\
\hline$\geq 9$ & 9 & 3.8 \\
\hline \multicolumn{3}{|l|}{ Marital status } \\
\hline Single & 42 & 17.9 \\
\hline Married & 178 & 75.7 \\
\hline Divorced & 7 & 3.0 \\
\hline Widowed & 8 & 3.4 \\
\hline
\end{tabular}

$L E=$ Egyptian pounds. participants in the age group $20-<40$ years were rated as excellent and good, and only $6.0 \%$ were rated as risky. In the other age group, 40-60 years, all participants were rated excellent and good, with a significant difference between the age groups in this section $(P$ $<0.05)$. As regards the item on eating habits the whole sample in both age groups scored at the risky level. In the exercises/fitness item, the majority of both groups were classified at the serious level, while others were rated as risky. On the stress management section around half of each group scored between excellent and good. In the section on safety a majority of both groups were rated at the risky level, while a minority had an excellent level, with more of the older age groups scoring excellent than the younger group $(P<0.05)$.

\begin{tabular}{|c|c|c|c|c|c|}
\hline \multirow[t]{3}{*}{ Section/Health lifestyle risk level } & \multicolumn{4}{|c|}{ Age group (years) } & \multirow[t]{3}{*}{$P$-value } \\
\hline & \multicolumn{2}{|c|}{$20-<40(n=130)$} & \multicolumn{2}{|c|}{ 40-60 $(n=105)$} & \\
\hline & No. & $\%$ & No. & $\%$ & \\
\hline \multicolumn{6}{|l|}{ Tobacco, alcohol \& other drugs } \\
\hline Excellent & 59 & 45.4 & 44 & 41.9 & $<0.05^{\mathrm{a}}$ \\
\hline Good & 65 & 50.0 & 61 & 58.1 & \\
\hline Risky & 6 & 4.6 & 0 & 0.0 & \\
\hline Serious & 0 & 0.0 & 0 & 0.0 & \\
\hline Eating habits & & & & & $\mathrm{n} / \mathrm{a}$ \\
\hline Excellent & 0 & 0.0 & 0 & 0.0 & \\
\hline Good & 0 & 0.0 & 0 & 0.0 & \\
\hline Risky & 130 & 100.0 & 105 & 100.0 & \\
\hline Serious & 0 & 0.0 & 0 & 0.0 & \\
\hline Exercises/fitness & & & & & $0.342^{\mathrm{b}}$ \\
\hline Excellent & 0 & 0.0 & 0 & 0.0 & \\
\hline Good & 0 & 0.0 & 0 & 0.0 & \\
\hline Risky & 30 & 23.1 & 21 & 20.0 & \\
\hline Serious & 100 & 76.9 & 84 & 80.0 & \\
\hline Stress management & & & & & $0.499^{b}$ \\
\hline Excellent & 68 & 52.3 & 54 & 51.4 & \\
\hline Good & 62 & 47.7 & 51 & 48.6 & \\
\hline Risky & 0 & 0.0 & 0 & 0.0 & \\
\hline Serious & 0 & 0.0 & 0 & 0.0 & \\
\hline Safety & & & & & $0.018^{b}$ \\
\hline Excellent & 7 & 5.4 & 15 & 14.3 & \\
\hline Good & 0 & 0.0 & 0 & 0.0 & \\
\hline Risky & 123 & 94.6 & 90 & 85.7 & \\
\hline Serious & 0 & 0.0 & 0 & 0.0 & \\
\hline
\end{tabular}

${ }^{a}$ Chi-squared test; ${ }^{b}$ Fisher exact test. 
Table 3 Scores of participants $(n=235)$ on individual readiness for change items and overall level of readiness for change preand post-intervention

\begin{tabular}{|c|c|c|}
\hline \multirow[t]{2}{*}{ Readiness for change items ${ }^{a}$ (scores) } & \multicolumn{2}{|c|}{$\%$ of drivers } \\
\hline & Pre-intervention & Post-intervention \\
\hline
\end{tabular}

3. Do you think that due to normal ageing, it's usual to take medications for heart disease, high blood pressure or type 2 diabetes that you don't have to take when you are younger?

Yes, I will be on 2 or more of these medications $(+3)$

Yes, I will keep out only on 1 of these medications $(+1)$

No, I will keep myself healthy, so I will not be on any of these medications $(-3)$

4. How do you explain the fact that you're in worse shape than when you were younger but haven't changed your habits at all?

I think it's my family history $(+1)$

I think it's that I'm less active $(+3)$

I think it's a natural consequence of aging $(-1)$

I don't know why it's happening (0)

6. Are you willing to join a gym today?

Yes $(+3)$

No $(-3)$

7. If someone told you that you'd need to throw away all the foods in your cupboards today and go shopping for different foods that are more appropriate to your goal, would you do it?

Yes $(+5)$

No $(-5)$

8. If an expert presents some information on diet and exercise that contradicts what you currently believe, what approach will you take?

Keep an open mind and give it a try $(+3)$

Ask a friend (0)

11. Are you ready to spend less time with people who offer little or no social support for your goals while spending more time with those who do offer support?

Yes $(+5)$

13. If a friend or loved one suggests that you don't have what it takes to get into great shape because you've failed before or for some other reason, what will be your response?

I can do it (+2)

I know I've got to make some changes but I'll take it one day at a time $(+5)$

Maybe I can't do it (-5)

14. Are you willing to wake up in the morning a bit earlier and stay up at night a bit later to accomplish your goals?

Yes $(+5)$

No $(-5)$

15. Are you willing to do at least 5 hours of physical activity each week?

Yes $(+5)$

No $(-5)$

Overall level of readiness for change (score) ${ }^{b}$

"It's important for the person to stop thinking and start doing" $(-20$ to +20$)$

"It doesn't look like the person really wants to change" (-61 to -21$)$

${ }^{a}$ Only items that showed significant changes between pre- and post-intervention are shown (numbers $3,4,6,7,8,11,13,14$ and 15). The remaining items (numbers $1,2,5$,

9,10 and 12) were unchanged pre- and post-intervention.

baired t-test: $t=-41.59, P<0.001$. 


\begin{tabular}{|c|c|c|}
\hline \multirow[t]{3}{*}{ Knowledge section/item } & \multicolumn{2}{|c|}{ Drivers' scores } \\
\hline & Pre-intervention & Post-intervention \\
\hline & Mean (SD) & Mean (SD) \\
\hline \multicolumn{3}{|l|}{ Knowledge about healthy lifestyles } \\
\hline $\begin{array}{l}\text { Nutrition (proper diet, weight management and keeping cholesterol } \\
\text { normal level) }\end{array}$ & $6.1(4.9)$ & $49.1(3.3)$ \\
\hline Physical exercises and fitness & $3.1(3.3)$ & $26.3(1.4)$ \\
\hline Tobacco & $3.4(3.8)$ & $32.4(1.5)$ \\
\hline Alcohol consumption & $0.2(0.5)$ & $4.0(0.0)$ \\
\hline Sexually transmitted diseases prevention & $3.4(2.3)$ & $31.8(0.6)$ \\
\hline Sleep & $0.8(1.0)$ & $7.0(0.0)$ \\
\hline Accident and injuries prevention & $5.0(3.5)$ & $41.0(0.0)$ \\
\hline Personal and general hygiene & $2.2(1.9)$ & $2.2(1.9)$ \\
\hline Stress management & $0.7(0.7)$ & $4.9(0.4)$ \\
\hline Periodical self-examination & $0.4(0.8)$ & $4.9(0.3)$ \\
\hline Total mean of healthy lifestyle items & $25.3(17.7)$ & $203.7(4.7)$ \\
\hline \multicolumn{3}{|l|}{ Knowledge about chronic diseases } \\
\hline Stroke prevention & $0.4(0.6)$ & $4.0(0.0)$ \\
\hline Diabetes mellitus prevention & $1.3(1.2)$ & $10.9(0.5)$ \\
\hline Cancer prevention & $2.6(2.2)$ & $25.1(2.4)$ \\
\hline Heart disease prevention & $1.2(1.4)$ & $15.0(1.9)$ \\
\hline Bronchial asthma prevention & $0.6(0.8)$ & $8.7(0.96)$ \\
\hline Total mean of chronic diseases items & $6.0(5.1)$ & $63.7(4.0)$ \\
\hline Total mean of CDL knowledge items & $31.3(21.8)$ & $209.7(7.8)$ \\
\hline
\end{tabular}

Paired t test: $t=158.0, P \leq 0.001$.

$S D=$ standard deviation

\section{Readiness for change}

Table 3 shows the overall readiness for change and the percentage responses pre- and post-intervention for individual items that showed significant changes. In terms of overall readiness for change before the intervention the majority of the study sample (88.1\%) had total scores in the lowest category, -61 to -21 ("It doesn't look like the person really wants to change"), while a minority scored between -20 to +20 . After the intervention, all the study participants scored in the intermediate category -20 to +20 , showing greater readiness for change ("It's important for the person to stop thinking and start doing"), which was a highly significant improvement in readiness for change scores before and after the intervention $(t=41.59, P<0.001)$.

\section{Chronic diseases of lifestyle knowledge}

Table 4 shows the means scores on chronic diseases of lifestyle knowledge pre- and post-intervention. The total mean of the CDL knowledge score in the pre-intervention [31.3 (SD 21.8)] was considerably less than the cut-off score (138) but in the post-intervention test the total mean knowledge score showed a highly significant improvement $[209.7($ SD 7.8) $](t=158.0, P \leq$ $0.001)$.

\section{Correlation between readiness for change and level of knowledge}

A positive correlation between the readiness for change scores and CDL knowledge scores pre- and post-intervention was shown $(P<0.01)($ Table 5).

\section{Discussion}

Due to their unhealthy lifestyles and lack of good nutritional options while travelling, truck drivers are categorized as one of the unhealthiest populations in the United States of America [21]. Researchers in China have also found that commercial drivers who work long days, in a high stress environment, remaining sedentary for long periods of time and lacking quality food options, suffered from poor nutrition and diet, in addition to irregular sleeping patterns [7]. Another study of a young male population of professional bus drivers revealed a high frequency of cardiovascular risk factors, such as obesity, as well as contributing functional characteristics, such sedentary behaviour [20]. In the present study the responses to the 


\begin{tabular}{|c|c|c|c|c|c|c|c|c|}
\hline \multirow[t]{3}{*}{ Variables/test } & \multicolumn{4}{|c|}{ Readiness for change } & \multicolumn{4}{|c|}{ Knowledge level } \\
\hline & \multicolumn{2}{|c|}{ Pre-intervention } & \multicolumn{2}{|c|}{ Post-intervention } & \multicolumn{2}{|c|}{ Pre-intervention } & \multicolumn{2}{|c|}{ Post-intervention } \\
\hline & $r$ & $P$-value & $r$ & $P$-value & $r$ & $P$-value & $r$ & $P$-value \\
\hline \multicolumn{9}{|l|}{ Readiness for change } \\
\hline Pre-intervention & 1.00 & & 0.73 & $<0.01$ & -0.23 & $<0.01$ & -0.04 & 0.58 \\
\hline Post-intervention & 0.73 & $<0.01$ & 1.00 & & -0.29 & $<0.01$ & -0.09 & 0.16 \\
\hline \multicolumn{9}{|l|}{ Knowledge level } \\
\hline Pre-intervention & -0.23 & $<0.01$ & -0.29 & $<0.01$ & 1.00 & & 0.69 & $<0.01$ \\
\hline Post-intervention & -0.04 & 0.581 & -0.09 & 0.16 & 0.69 & $<0.01$ & 1.00 & \\
\hline
\end{tabular}

Pearson correlations, 2-tailed.

sections on eating habits, exercises/ fitness and safety revealed a risky level of health lifestyles among microbus drivers in Egypt.

Readiness for change was low before the intervention for more than $88 \%$ of respondents. Many barriers may influence drivers' motivation and consequently their readiness for change directed towards healthy lifestyles. The barriers in the present study could include low income and poor knowledge concerning healthy lifestyles before the intervention. Low income could deter drivers from eating quality meals, from practising exercise regularly or even from maintaining their vehicle's safety, and could lead to higher workload hours which affect their rest and sleep patterns. Meanwhile, the low knowledge level regarding healthy lifestyles, CDL and prevention may create negative attitudes, careless behaviour and feelings of worthlessness that are clearly mirrored in the safety risk finding.

Knowledge about chronic diseases of lifestyle was poor pre-intervention, but increased significantly after drivers had received the health education module. Drivers need to have better access to health education resources and technology; interventions to reduce risk factors and prevent chronic disease can be extremely successful $[9,20,22]$. Researchers have proposed that behaviour change coaching complements disease education coaching programmes, which are considered vital but alone do not necessarily translate into successful self-management strategies and are not sufficient for the development of the long-term behaviour change required in those with chronic illness $[9,13]$. Other authors have suggested that "tailoring a lifestyle intervention to a person's stage of change may enhance its effectiveness in changing diet and exercise behaviours" [12,23]. Studies have found that adherence to health-related lifestyle changes is less than satisfactory; thus interventions that aim to achieve health behaviour change need to be appropriate to the client's readiness to make the required change. Clients without chronic conditions or those at risk of developing a chronic condition also need personal skills to be full partners in managing their own health $[2,6,13]$.

Knowledge regarding CDL and their prevention as well as healthy lifestyles was improved post-intervention in the present study sample. Also, a significant positive correlation between the level of CDL knowledge and level of readiness for change pre-post-intervention was shown. The intervention was based on a self-learning booklet which each driver received and was encouraged to study without any obligations or restrictions. Hence, the information was self-managed with the researcher as facilitator. We conclude that availability of health information for long-distance microbus drivers at their work site may be valuable for health promotion and disease prevention.

To sum up, the majority of the microbus drivers in this study recorded risky scores regarding eating habits, exercises/fitness and safety. A positive correlation was found between the levels of CDL knowledge and readiness for change among the drivers before and after the educational intervention. Further research is needed to implement such interventions on different vehicles drivers, by investigating job attributes that hinder readiness for change in their health lifestyles.

\section{Acknowledgements}

Funding: No external sources of funding for the researcher were obtained.

Competing interests: None declared.

\section{References}

1. Ford ES et al. Healthy living is the best revenge: findings from the European Prospective Investigation into Cancer and Nutrition-Potsdam study. Archives of Internal Medicine, 2009, 169(15):1355-1362.
2. King DE et al Adherence to healthy lifestyle habits in US adults, 1988-2006. American Journal of Medicine, 2009, 122(6):528-534.

3. Derman EW et al. Healthy lifestyle interventions in general practice. South African Family Practice, 2008, 50(4):6-12. 
4. Projections of mortality and burden of disease to 2030. Geneva, World Health Organization, 2007.

5. Assaad R, Barsoum G. Youth exclusion in Egypt: in search of "second chances". Washington DC, Wolfensohn Center for Development, Brookings Institution, 2007 (Middle East Youth Initiative Working Paper No. 2/2007).

6. Commercial truck and bus safety synthesis program. Washington DC, Transportation Research Board of the National Academies, 2007.

7. Wong CK et al. The impact of work nature, lifestyle, and obesity on health-related quality of life in Chinese professional drivers. Journal of Occupational and Environmental Medicine, 2012, 54(8):989-994.

8. Kjeld, B.P. The Healthy Bus project in Denmark: need for an action potential assessment. Health Promotion International, 2004, 19(2):205-213

9. Saltzman GM, Belzer MH, eds. Truck driver occupational safety and health: 2003 conference report and selective literature review. Cincinnati, Ohio, Department of Health and Human Services, 2007 (NIOSH Publication No. 2007-120).

10. Orris $\mathrm{P}$ et al. Literature review on health and fatigue issues associated with commercial motor vehicle driver hours of work. Washington DC, Transport Research Board of the National Academies, 2005 (CTBSSP Synthesis 9).

11. Hirata RP et al. General characteristics and risk factors of cardiovascular disease among interstate bus drivers. Scientific World Journal, 2012. doi: 10.1100/2012/216702.

12. Shumaker SA, Ockene JK, Riekert KA, eds. The handbook of health behavior change, 3rd ed. New York, Springer Publishers, 2009.

13. Medynskiy Y, Yarosh S, Mynatt E. Five strategies for supportt ing healthy behavior change. In: Proceedings of the 2011 Conference on Human Factors in Computing Systems. Extended abstracts on human factors in computing systems. New York, Association for Computing Machinery, 2011.
14. Alters S, Schiff W, eds. Applying concepts for healthy living: a workbook. Burlington, Massachusetts, Jones and Bartlett Publishers, 2011.

15. Patient Education Institute [website] (www.mufasser.com, accessed 23 October 2013).

16. Aml GA. Health lifestyle. Manama, Bahrain, Ministry of Health, 2002.

17. ICSI guideline. Healthy lifestyles, 4th ed. Bloomington, Minnesota, Institute for Clinical Systems Improvement, 2011 (http:// www.icsi.org (https://www.icsi.org/_asset/4qjdnr/HealthyLifestyles.pdf, accessed 23 October 2013).

18. National guideline on primary prevention of chronic diseases of lifestyle. Your guide to lowering blood pressure. Washington DC, US Department of Health and Human Services, National Institutes of Health, 2005.

19. Readiness for change questionnaire. Lifestyle Management and Nutrition [online] (www.lifestylenutritionvt.com/.../readiness_for_change_questionnaire_-_I..., accessed 18 September 2013).

20. Al-Hazzaa HM et al. Physical activity, sedentary behaviors and dietary habits among Saudi adolescents relative to age, gender and region. International Journal of Behavioral Nutrition and Physical Activity, 2011, 8:140. doi: 10.1186/1479-5868-8-140.

21. Levy S. American crisis-health of our nation's truck drivers. Health Care Reform Magazine, 1 February 2012 (http:// www.healthcarereformmagazine.com/article/american-crisis-health-of-our-nation-s-truck-drivers.html, accessed 22 October 213).

22. Preventing and managing chronic disease: Ontario's framework. Toronto, Ontario, Canada, Ministry of Health and Long-Term Care, 2007 (http://www.health.gov.on.ca/en/pro/programs/cdpm/pdf/framework_full.pdf, accessed 22 October 213).

23. Noncommunicable diseases country profiles 2011. WHO global report. Geneva, World Health Organization, 2011. 